\title{
Schedule-Induced Polydipsia: Searching for the Endophenotype of Compulsive Behavior
}

\author{
Pilar Flores, Ana Sánchez-Kuhn, Ana Merchán, Olga Vilches, Sergio García-Martín, \\ Margarita Moreno* \\ Department of Psychology, University of Almería, Agrifood Campus of International Excellence CeiA3, \\ La Cañada, Spain \\ Email: ${ }^{*}$ mgmoreno@ual.es
}

Received 1 May 2014; revised 2 June 2014; accepted 15 June 2014

Copyright @ 2014 by authors and Scientific Research Publishing Inc.

This work is licensed under the Creative Commons Attribution International License (CC BY). http://creativecommons.org/licenses/by/4.0/

(c) (i) Open Access

\section{Abstract}

The development of excessive and persistent drinking under intermittent food-reinforcement schedules, known Schedule-induced polydipsia (SIP), has been proposed as a successful animal model to study compulsive behaviors. On the last decade, we have been working in our laboratory on the stratification of the compulsive rats on SIP in order to know whether differences in the acquisition of compulsive drinking behavior could predict alterations in other behavioral measures as well as in the neurochemical function typically associated with compulsive spectrum disorders. The aim of this review is to collate the main findings relevant to the characterization and use of the high compulsive drinking rats (HD) in SIP as a possible compulsive endophenotype. The review of the genetic, behavioral and neurochemical differences found in the selection allows us to conclude that HD rats could be a valid model for studying the compulsive phenotype and modelling psychopathology common to a variety of compulsivity spectrum disorders such as obsessivecompulsive disorder (OCD), schizophrenia and alcohol abuse.

\section{Keywords}

Compulsivity, Endophenotype, Schedule-Induced Polydipsia, Obsessive-Compulsive Disorder, Schizophrenia

\section{Introduction}

Compulsivity represents the performance of repetitive and functionally impairing overt or covert behavior without adaptive function, performed in a habitual or stereotyped fashion, either according to rigid rules or as a means of avoiding perceived negative consequences [1]. Obsessive-compulsive disorder (OCD) is one of the ${ }^{*}$ Corresponding author.

How to cite this paper: Flores, P., Sánchez-Kuhn, A., Merchán, A., Vilches, O., García-Martín, S. and Moreno, M. (2014) Schedule-Induced Polydipsia: Searching for the Endophenotype of Compulsive Behavior. World Journal of Neuroscience, 4 , 253-260. http://dx.doi.org/10.4236/wjns.2014.43029 
most characteristic clinical examples of compulsivity; however this behavior is also present across different neuropsychiatric disorders, such as attention deficit-hyperactivity disorder (ADHD), schizophrenia, depression, compulsive gambling, eating disorders and substance abuse [2]. Furthermore, compulsivity is also present in excoriation and binge-eating disorder, both of which have been recently categorised as such in the fifth edition of the Diagnostic and Statistical Manual of Mental Disorders [3].

Because of its characteristics of "excessiveness" and "persistence" schedule-induced polydipsia (SIP), has been presented as an useful model to study those neuropsychiatric disorders characterized by the presence of compulsive behavior such as OCD (see for review [4] [5]), schizophrenia [6] [7] and alcohol abuse [8]-[10].

Schedule-induced polydipsia can then be defined as the excessive drinking developed by food-deprived animals exposed to intermittent food-reinforcement schedules [11]. The drinking behavior displayed on SIP is not related to regulatory needs, given that the animals are not water deprived and there is no arranged contingency between drinking and food delivery. An excessive non-regulatory drinking, non-related to homeostatic needs or a physiological cause, has also been observed in humans among different psychiatric disorders sharing impulsive-compulsive symtomatology such as OCDs, schizophrenia and ADHD [12]-[15].

Schedule-induced polydipsia has been proposed as the prototype of adjunctive behavior, a category of behavior that would include all activities occurring in reinforcement schedules with no direct relationship to reinforcement delivery [16]. A main characteristic of schedule-induced polydipsia is the bitonic relation between the amount of drinking and inter-reinforcement interval length [17] [18]. The phenomenon of adjunctive behavior has been documented in different animal species, including humans, and with different reinforcement schedules and types of reinforcers [19]. Other behaviors have been shown to be functionally similar to schedule-induced polydipsia, including aggression [20], excessive running [21], induced stereotypy [22] and pica [23]. Although different factors, such as the state of food deprivation or the inter-food interval length influence the SIP acquisition and expression [16] [18] [24] [25] data from our laboratory have shown that the optimal Fixed Time (FT) intervals for inducing a high rate of drinking are FT-30s [26] and FT-60s [27].

Pre-existing differences among individuals have been observed in schedule-induced polydipsia (see Figure 1). However, those differences are not related to regulatory drinking intake, as shown by the lack of differences in water intake between HD (high drinkers) and LD (low drinkers) in home cages during 24 hours and during 1 hour after 23 hours of water restriction (see Figure 2). Several experiments have shown that not all rats, although identical in strain, sex and age, submitted to the same conditions develop adjunctive drinking, and among those animals that do develop it, considerable individual differences in the amount of fluid intake and licks have been found [26]-[31].

The aim of this review is to collate the main findings relevant to the characterization and use of the high compulsive drinking rats (HD) in SIP as a possible compulsive endophenotype. To achieve that objective we review the genetic, behavioral and neurochemical differences found by the stratification of rats according to individual differences in the acquisition of compulsive drinking on SIP.

\section{Genetic Differences: Are Rat Strains Different in SIP Acquisition?}

We have found that the quantity of SIP developed could vary across different inbred and outbred rat strains. These differences in SIP behavior may reflect an association with other behavioral or neurochemical differences characteristic in the rat strains tested. It has been reported that rats that show a high locomotor response to novelty (high responders) and displayed high d-amphetamine self-administration also developed faster and achieved higher levels of SIP than low responsive rats [32] [33]. Different lines of inbred Fisher 344 (F344) and Lewis (LEW) rats also exhibit different levels of SIP [34] [35]. The F344 strain, hyper-responsive in relation to HPA activity acquired faster and drank more than LEW strain, which was hypo-responsive to HPA. Lister Hooded compared to Wistar rats typically displayed higher levels of exploratory behavior and lower levels of anxiety [36] [37]. Wistar rats more readily acquired SIP and exhibited a greater level of water drinking than Lister Hooded [38] [39]. Moreover, the SIP task has proved to be sensitive to genotypic differences in alcohol consumption, revealing that strain differences in a SIP alcohol drinking paradigm between C57BL/6J and DBA/2J mice are the same as those obtained using more traditional methods of alcohol self-administration [10]. Selective breeding of Roman high-(RHA) and low (RLA) rats for rapid vs extremely poor acquisition of active avoidance behavior in a shuttle-box has generated two phenotypes with different emotional and motivational profiles. Roman rat strains include differences in anxiety, novelty seeking, stress responsivity and susceptibility 


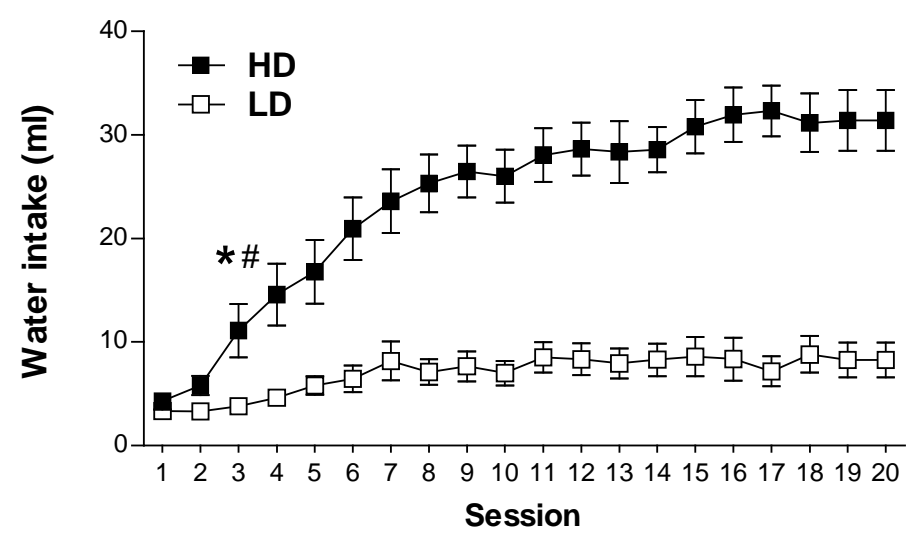

(a)

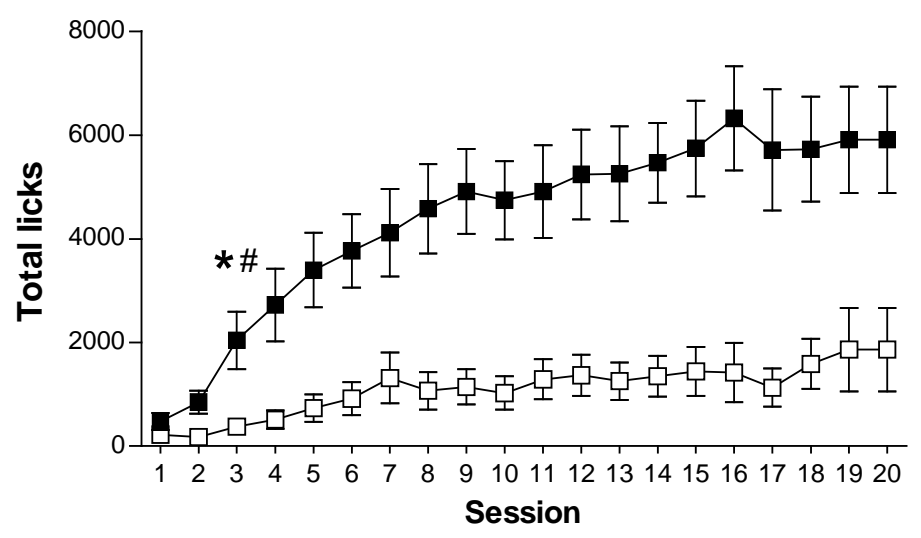

(b)

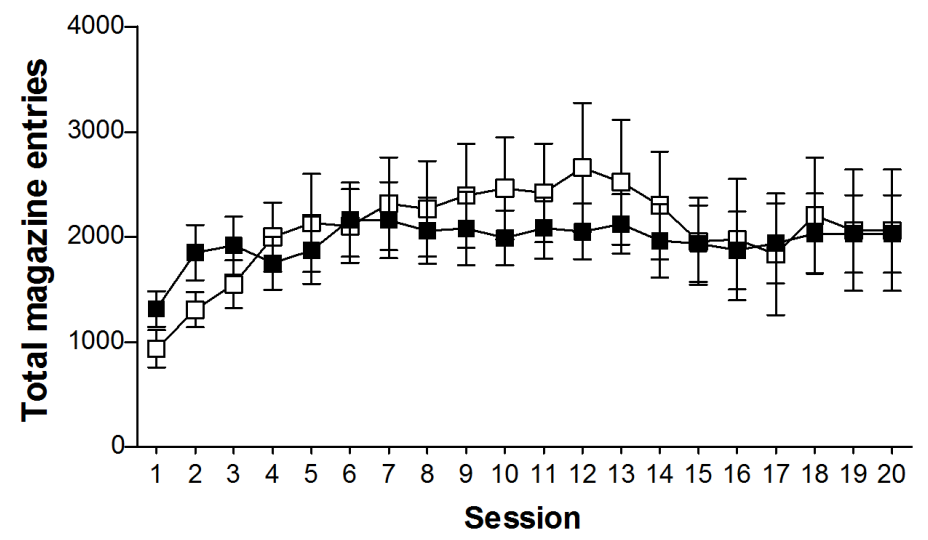

(c)

Figure 1. The mean ( \pm SEM) water intake (a), total licks (b) and total magazine entries in the food magazine (c) in FT-60 s across 20 sessions of SIP in HD and LD. (*) Statistical analyses indicate significant differences between HD and LD from that session onward; (\#) Significant differences from Session 1.

to addictive-substances [40]-[43]. RHA rats show an increased acquisition of compulsive drinking on SIP, a higher impulsive choice in a delay discounting task and poor inhibitory control as shown by increased trend to premature responses in the 5-choice serial reaction time task (5-CSRT) [31]. In a recent study, spontaneously hypertensive rats, characterized as hyperactive and impulsive, displayed increased drinking in SIP compared to the controls Wistar Kyoto rats [44].

All of these studies showed that SIP procedure select phenotypes of rats that have shown differences in deficits on inhibitory control responses by impulsive/compulsive tasks or vulnerability to drug use, pointing towards 


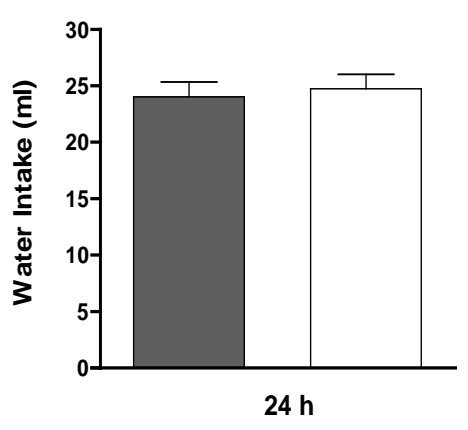

(a)

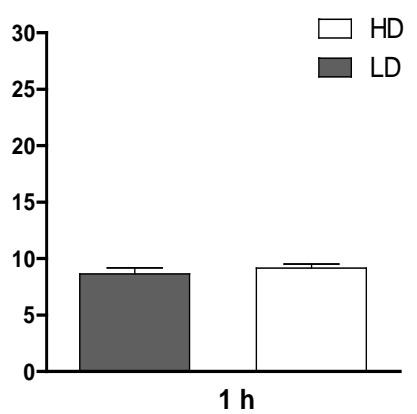

(b)

Figure 2. Average water intake in milliliters of HD (white bars) and LD (black bars) in home cages during $24 \mathrm{~h} \mathrm{(a)}$ and during $1 \mathrm{~h}$ after $23 \mathrm{~h}$ of water restriction (b). The data are mean \pm SEM.

a positive correlation between this deficit and the amount of drinking on SIP. However, further research is needed to better characterize the compulsive phenotype of HD rats.

\section{Which Behavioral Traits Are Present in Compulsive HD Rats? Behavioral Differences}

Is it possible to predict which animals will show a propensity to compulsive behavior from their levels of SIP? On the last decade, we have been working in our laboratory on the selection of the compulsive rats on SIP. The procedure for stratification of Wistar rats is done after 20 days of SIP testing. Then it is possible to differentiate two groups of rats, one with high or excessive drinking (HD) and a second group with low drinking or not SIP acquisition (LD). The selection of the subpopulations of rats is based on whether their rates of drinking (average for each animal on the last 3 SIP sessions) were above or below the group median, respectively (see Figure 1). In different experiments, after SIP acquisition HD and LD rats have been tested in different procedures and tasks to assess behaviors and behavioral traits, such as novelty reactivity, anxiety or deficit in inhibitory control related to symptomatology and vulnerability to compulsive spectrum disorders. HD and LD rats did not differ in novelty reactivity, as no differences were found between them on spontaneous locomotor response to a novel environment on activity cages, measured as the number of photo-beam breaks over a 60 min period [29]. HD and LD rats did not differ in anxiety response assessed by the percent of time spent on the open arms or by the percent of open-arm entries in the elevated plus maze (EPM). This test evaluates anxiety by confronting the rats with novel environments in which they must cope with two opposing tendencies: their innate curiosity to explore new environments and their natural avoidance of open spaces. This result indicates that individual differences in SIP were not paralleled by differences in anxiety like-behaviors such as measured by EPM [27].

We have also assessed the reward seeking process by using a conditioned place preference (CPP) to d-amphetamine; HD and LD were assessed in a CPP test against preferences. The first association for all animals was amphetamine. Thus, on days 1, 3, 5 and 7 rats were administered amphetamine and placed in the less preferred compartment on the first day, for $30 \mathrm{~min}$. On days 2, 4, 6 and 8, the rats received saline and were confined to the initially preferred compartment during the same time period. The test comprised a third stage or post-conditioning, which was similar to day 1 of the procedure. Rats were allowed to freely explore the entire apparatus for 15 min and the time the animal spent in each of the compartments was recorded. Results indicated that HD and LD profiles were similar in CPP reflecting the same levels of reward seeking process (see Figure 3) [45].

Individual differences in impulsivity between HD and LD animals have also been tested in two impulsivity paradigms. The results indicated that HD animals exhibit more impulsive decision making in a delay discounting task [26] [46] and less inhibitory control on the 5-choice serial reaction time task, as demonstrated by increased perseverative-compulsive responses under extinction conditions, and an increased sensitivity to d-amphetamine effects in premature-impulsive response in the same task [29]. Furthermore, recent unpublished results from our lab have revealed that HD rats required more trials to learn the reversal phase of a within-session spatial reversal learning task than LD rats, thus indicating deficits in cognitive flexibility.

HD and LD rats did not differ in the behavioral traits related with anxiety, novelty reactivity or reward seeking. However, as indicated by the differences commented above, it seems that there is a positive correlation 


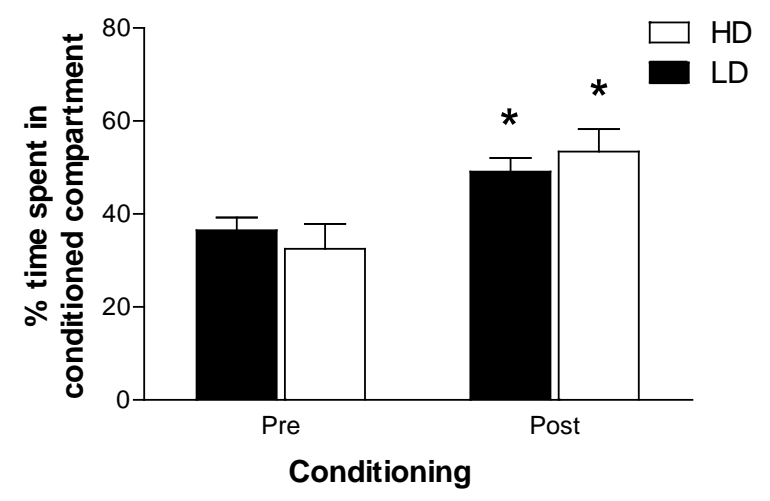

Figure 3. Percentage of time spent in the conditioned compartment by HD and LD previous and after $\mathrm{d}$-amphetamine conditioning. The data are mean $\pm \mathrm{SEM} ;{ }^{*} \mathrm{p}<0.05$ indicates statistical significance.

between inhibitory control deficits, including cognitive inflexibility, and the level of SIP acquired. Then, coming back to the question raised at the beginning of this section, it seems that the level of SIP acquisition could indicate a propensity to compulsive behaviors. Therefore the study of HD animals in comparison with LD could be a useful model for studying the specific neurobehavioral mechanisms of impulsive/compulsive behaviors, discarding the influence of other behavioral traits such as anxiety, novelty reactivity and reward seeking.

\section{Neurochemical Function in Compulsive SIP Rats}

Data from our laboratory have shown that individual differences in SIP development are related to neurochemical differences linked to the dopaminergic and serotoninergic systems. Rats classified according to SIP acquisition, as high drinkers (HD) and low drinkers (LD), manifest differences in pharmacological challenge with dopaminergic drugs. HD animals reduced SIP after $0.5 \mathrm{mg} / \mathrm{kg}$ of d-amphetamine and $10 \mathrm{mg} / \mathrm{kg}$ of cocaine, while in LD rats SIP was reduced only at the higher dose of $2 \mathrm{mg} / \mathrm{kg}$ of d-amphetamine [27]. Moreover, by autoradiography analyses we have found an opposite pattern of binding in dopamine D1 and D2 receptors between HD and LD rats in the nucleus accumbens, medial prefrontal cortex, amygdala and ventral tegmental area; HD showed higher binding for D2 receptors and lower binding for D1 receptors compared LD rats, also associated with an elevated c-Fos expression in the medial prefrontal cortex of HD rats selected according to SIP performance [30]. The differences observed in compulsive drinking on SIP could result from altered mesolimbic functioning in HD animals, as indicated by hyperactivity in serotonergic and noradrenergic neurotransmission in the amygdala and the hypoactivity in dopamine neurotransmission in nucleus accumbens and prefrontal cortex in post-mortem analyses of these animals compared to LD rats [29]. These results are in accordance with neurochemical data from RHA rats, characterized by elevated SIP acquisition, that showed higher levels of 5-HT and NE and lower levels of DA activity in the striatum and the nucleus accumbens under basal conditions in comparison with RLA rats [31].

Pharmacological treatments in humans have shown that compulsive symptoms across different psychiatric disorders respond either to serotonin reuptake inhibitors and atypical antipsychotics or the combination of both. Indeed, evidence from animal and human studies implicates 5-HT2 receptors in compulsivity (for review see [48] [49]). Data from our laboratory have shown that HD rats showed a reduction in compulsive drinking on SIP following the systemic administration of the selective serotonin reuptake inhibitor citalopram, but not to the selective noradrenaline reuptake inhibitor atomoxetine. Furthermore, the systemic administration of the serotonin 5-HT2A/C receptor agonist DOI induced a dose-dependent reduction of compulsive water intake in HD rats on SIP, without affecting LD rat behavior. However, the induced reduction of compulsive drinking by DOI observed in HD rats was reversed by the administration of the serotonin 5-HT2A receptor antagonist ketanserin and the highly selective receptor antagonist M100907, but not by the serotonin 5-HT2C receptor antagonist SB242084, which suggests that serotonin 5-HT2A receptors may have a relevant participation in the inhibition of compulsive behavior exhibited by HD rats on SIP [47].

\section{Conclusions}

In SIP procedure, hungry but not thirsty animals exposed to an intermittent food delivery consume large 
amounts of water during the experimental sessions. Because of its characteristics of excessiveness and persistence SIP has been proposed as a successful model to study those neuropsychiatric disorders characterized by the presence of compulsive behavior such as: obsessive-compulsive disorder (OCD), schizophrenia, and alcohol abuse [28].

Data reviewed here have shown that HD rats have alterations in the dopaminergic and serotonergic frontostriatal neurocircuitry as occurs in compulsive spectrum disorders. We have also summarized data from behavioral studies on novelty reactivity, anxiety, reward seeking and impulsive-compulsive behaviors. HD rats present lack of inhibitory control and inappropriate persistence measured as: premature and perseverative responses, in 5-choice serial reaction time task, impulsivity choice in a delay discounting task and cognitive inflexibility assessed in a spatial reversal learning task. The amount of SIP acquisition seems to be a good predictor of traits related to inhibitory control deficits.

Future studies have to address if the compulsive drinking displayed by HD rats on SIP is due to an alteration in the stopping process or the establishment of an inappropriate habit, therefore we can have a better knowledge of the neurochemical alterations involved in the activation or inhibition processes responsible for that excessive SIP behavior and whether new therapeutic strategies are able to modify that compulsive phenotype.

\section{Acknowledgements}

This study was funded by a grant from the Ministerio de Economía y Competitividad, Spanish Government (PSI2012-31660).

\section{References}

[1] Fineberg, N.A., Chamberlain, S.R., Goudriaan, A.E., Stein, D.J., Vanderschuren, L.J., Gillan, C.M., Shekar, S., Gorwood, P.A., Voon, V., Morein-Zamir, S., Denys, D., Sahakian, B.J., Moeller, F.G., Robbins, T.W. and Potenza, M.N. (2014) New Developments in Human Neurocognition: Clinical, Genetic, and Brain Imaging Correlates of Impulsivity and Compulsivity. CNS Spectrums, 19, 69-89. http://dx.doi.org/10.1017/S1092852913000801

[2] Skodol, A.E. and Oldham, J.M. (1996) Phenomenology, Differential Diagnosis, and Comorbidity of Impulsive-Compulsive Spectrum of Disorders. In: Oldham, J.M., Hollander, E. and Skodol, A.E., Eds., Impulsivity and Compulsivity, American Psychiatric Press, Inc., Washington, 1-36.

[3] American Psychiatric Association (2013) Diagnostic and Statistical Manual of Mental Disorders. 5th Edition, American Psychiatric Press, Washington DC. http://www.dsm5.org/about/Pages/DSMVOverview.aspx

[4] Platt, B., Beyer, C.E., Schechter, L.E. and Rosenzweig-Lipson, S. (2008) Schedule-Induced Polydipsia: A Rat Model of Obsessive-Compulsive Disorder. Current Protocols in Neuroscience, $\mathbf{9}$. http://dx.doi.org/10.1002/0471142301.ns0927s43

[5] Woods, A., Smith, C., Szewczak, M., Dunn, R.W., Cornfeldt, M. and Corbett, R. (1993) Selective Serotonin Re-Uptake Inhibitors Decrease Schedule-Induced Polydipsia in Rats: A Potential Model for Obsessive-Compulsive Disorder. Psychopharmacology, 112, 195-198. http://dx.doi.org/10.1007/BF02244910

[6] Hawken, E.R. and Beninger, R.J. (2014) The Amphetamine Sensitization Model of Schizophrenia Symptoms and Its Effects on Schedule-Induced Polydipsia in the Rat. Psychopharmacology, 231, 2001-2008. http://dx.doi.org/10.1007/s00213-013-3345-9

[7] Hawken, E.R., Delva, N.J., Reynolds, J.N. and Beninger, R.J. (2011) Increased Schedule-Induced Polydipsia in the Rat Following Subchronic Treatment with MK-801. Schizophrenia Research, 125, 93-98. http://dx.doi.org/10.1016/j.schres.2010.07.022

[8] Ford, M.M. (2014) Applications of Schedule-Induced Polydipsia in Rodents for the Study of an Excessive Ethanol Intake Phenotype. Alcohol, 48, 265-276. http://dx.doi.org/10.1016/j.alcohol.2014.01.005

[9] Gilpin, N., Badia-Elder, N., Elder, R. and Stewart, R. (2008) Schedule-Induced Polydipsia in Lines of Rats Selectively Bred for High and Low Ethanol Preference. Behavioral Genetics, 38, 515-524. http://dx.doi.org/10.1007/s10519-008-9224-1

[10] Mittleman, G., Van Brunt, C.L. and Matthews, D.B. (2003) Schedule-Induced Ethanol Self-Administration in DBA/2J and C57BL/6J Mice. Alcoholism: Clinical and Experimental Research, 27, 918-925. http://dx.doi.org/10.1111/j.1530-0277.2003.tb04416.x

[11] Falk, J.L. (1961) Production of Polydipsia in Normal Rats by an Intermittent Food Schedule. Science, 133, $195-196$. http://dx.doi.org/10.1126/science.133.3447.195

[12] Dundas, B., Harris, M. and Narasimhan, M. (2007) Psychogenic Polydipsia Review: Etiology, Differential, and Treat- 
ment. Current Psychiatry Reports, 9, 236-241. http://dx.doi.org/10.1007/s11920-007-0025-7

[13] Oades, R.D., Daniels, R. and Rascher, W. (1998) Plasma Neuropeptide-Y Nevels, Monoamine Metabolism, Electrolyte Excretion and Drinking Behavior in Children with Attention-Deficit Hyperactivity Disorder. Psychiatry Research, 80, 177-186. http://dx.doi.org/10.1016/S0165-1781(98) 00064-X

[14] IIllowsky, B.P. and Kirch, D.G. (1988a) New Information on Polydipsia and Hyponatremia in Psychiatric Patients. The American Journal of Psychiatry, 145, 1039. http://ajp.psychiatryonline.org/article.aspx?articleid=165252

[15] Illowsky, B.P. and Kirch, D.G. (1988b) Polydipsia and Hyponatremia in Psychiatric Patients. The American Journal of Psychiatry, 145, 675-683. http://ajp.psychiatryonline.org/article.aspx?articleid=165084

[16] Falk, J.L. (1971) The Nature and Determinants of Adjunctive Behavior. Physiology \& Behavior, 6, 577-588. http://dx.doi.org/10.1016/0031-9384(71)90209-5

[17] Flores, P. and Pellón, R. (1995) Rate-Dependency Hypothesis and the Rate Decreasing Effects of D-Amphetamine on Schedule-Induced Drinking. Behavioral Pharmacology, 6, 16-23. http://dx.doi.org/10.1097/00008877-199501000-00004

[18] Flory, R.K. (1971) The Control of Schedule-Induced Polydipsia: Frequency and Magnitude of Reinforcement. Learning and Motivation, 2, 215-227. http://dx.doi.org/10.1016/0023-9690(71)90022-1

[19] Falk, J.L. and Kupfer, A.S. (1998) Adjunctive Behavior: Application to the Analysis and Treatment of Behavior Problems. In: O’Donohue, W., Ed., Learning and Behavior Therapy, Allyn and Bacon, Boston, 334-351.

[20] Looney, T.A. and Cohen, P.S. (1982) Aggression Induced by Intermittent Positive Reinforcement. Neuroscience \& Biobehavioral Reviews, 6, 15-37. http://dx.doi.org/10.1016/0149-7634(82)90004-5

[21] Collier, G. and Levitsky, D.A. (1968) Operant Running as a Function of Deprivation and Effort. Journal of Comparative and Physiological Psychology, 66, 522-523. http://dx.doi.org/10.1037/h0026351

[22] Mittleman, G., Jones, G.H. and Robbins, T.W. (1991) Sensitization of Amphetamine-Stereotypy Reduces Plasma Corticosterone: Implications for Stereotypy as a Coping Response. Behavioral and Neural Biology, 56, 170-182. http://dx.doi.org/10.1016/0163-1047(91)90584-D

[23] Wilson, J.F. and Cantor, M.B. (1987) An Animal Model of Excessive Eating: Schedule-Induced Hyperphagia in FoodSatiated Rats. Journal of the Experimental Analysis of Behavior, 47, 335-346. http://dx.doi.org/10.1901/jeab.1987.47-335

[24] López-Grancha, M., López-Crespo, G., Venero, C., Cañadas, F., Sánchez-Santed, F., Sandi, C. and Flores, P. (2006) Differences in Corticosterone Level Due to Inter-Food Interval Length: Implications for Schedule-Induced Polydipsia. Hormones and Behaviour, 49, 166-172. http://dx.doi.org/10.1016/j.yhbeh.2005.05.019

[25] López-Crespo, G., Rodríguez, M., Pellón, R. and Flores, P. (2004) Acquisition of Schedule-Induced Polydipsia by Rats in Proximity to Upcoming Food Delivery. Animal Learning \& Behavior, 32, 491-499. http://dx.doi.org/10.3758/BF03196044

[26] Cardona, D., López-Grancha, M., López-Crespo, G., Nieto-Escámez, F., Sánchez-Santed, F. and Flores, P. (2006) Vulnerability of Long-Term Neurotoxicity of Chlorpyrifos: Effect on Schedule-Induced Polydipsia and a Delay Discounting Task. Psychopharmacology, 189, 47-57. http://dx.doi.org/10.1007/s00213-006-0547-4

[27] López-Grancha, M., Lopez-Crespo, G., Sanchez-Amate, M.C. and Flores, P. (2008) Individual Differences in Schedule-Induced Polydipsia and the Role of Gabaergic and Dopaminergic Systems. Psychopharmacology, 197, 487-498. http://dx.doi.org/10.1007/s00213-007-1059-6

[28] Moreno, M. and Flores, P. (2012) Schedule-Induced Polydipsia as a Model of Compulsive Behavior: Neuropharmacological and Neuroendocrine Bases. Psychopharmacology, 219, 647-659. http://dx.doi.org/10.3758/BF03196044

[29] Moreno, M., Gutiérrez-Ferre, V.E., Ruedas, L., Campa, L., Suñol, C. and Flores, P. (2012) Poor Inhibitory Control and Neurochemical Differences in High Compulsive Drinker Rats Selected by Schedule-Induced Polydipsia. Psychopharmacology, 219, 661-672. http://dx.doi.org/10.1007/s00213-011-2575-y

[30] Pellón, R., Ruíz, A., Moreno, M., Claro, F., Ambrosio, E. and Flores, P. (2011) Individual Differences in Schedule-Induced Polydipsia: Neuroanatomical Dopamine Divergences. Behavioural Brain Research, 217, 195-201. http://dx.doi.org/10.1016/j.bbr.2010.10.010

[31] Moreno, M., Cardona, D., Gómez, M.J., Sánchez-Santed, F., Tobeña, A., Fernández-Teruel, A., Flores, P., et al. (2010) Impulsivity Characterization in the Roman High- and Low-Avoidance Rat Strains: Behavioral and Neurochemical Differences. Neuropsychopharmacology, 35, 1198-208. http://dx.doi.org/10.1038/npp.2009.224

[32] Hooks, M.S., Jones, G.H., Juncos, J.L., Neill D.B. and Justice, J.B. (1994) Individual Differences in Schedule-Induced and Conditioned Behaviors. Behavioural Brain Research, 60, 199-209. http://dx.doi.org/10.1016/0166-4328(94)90148-1

[33] Piazza, P.V., Mittleman, G., Deminiere, J.M., Le Moal, M. and Simon, H. (1993) Relationship between Schedule-In- 
duced Polydipsia and Amphetamine Intravenous Self-Administration. Individual Differences and Role of Experience. Behavioural Brain Research, 55, 185-193. http://dx.doi.org/10.1016/0166-4328(93)90114-6

[34] DeCarolis, N.A., Myracle, A., Erbach, J., Glowa, J., Flores, P. and Riley, A.L. (2003) Strain-Dependent Differences in Schedule-Induced Polydipsia: An Assessment in Lewis and Fischer Rats. Pharmacology Biochemistry and Behaviour, 74, 755-763. http://dx.doi.org/10.1016/S0091-3057(02)01071-7

[35] Stöhr, T., Szuran, T., Welzl, H., Pliska, V., Feldon, J. and Pryce, C.R. (2000) Lewis/Fischer Rat Strain Differences in Endocrine and Behavioral Responses to Environmental Challenge. Pharmacology Biochemistry and Behavior, 67, 809819. http://dx.doi.org/10.1016/S0091-3057(00)00426-3

[36] Clemens, L.E., Jansson, E.K.H., Portal, E., Riess, O. and Nguyen, H.P. (2014) A Behavioral Comparison of the Common Laboratory Rat Strains Lister Hooded, Lewis, Fischer 344 and Wistar in an Automated Homecage System. Genes, Brain and Behavior, 13, 305-321. http://dx.doi.org/10.1111/gbb.12093

[37] Ennaceur, A., Michalikova, S., Bradford, A. and Ahmed, S. (2005) Detailed Analysis of the Behavior of Lister and Wistar Rats in Anxiety, Object Recognition and Object Location Tasks. Behavioural Brain Research, 159, 247-266. http://dx.doi.org/10.1016/j.bbr.2004.11.006

[38] Merchán, A., Navarro, S.V., García, S., Moreno, M. and Flores, P. (2013) Tryptophan Depletion Diet in Low versus High Drinker Rats Selected by Schedule-Induced Polydipsia. Behavioural Pharmacology, 24, e28. http://dx.doi.org/10.1097/01.fbp.0000434780.18559.cb

[39] Cardona, D., de Oca, L.M., Moreno, M., Flores, P. and Sánchez-Santed, F. (2009) Strain Differences in Schedule-Induced Polydipsia. Behavioural Pharmacology, 20, s58.

[40] Fattore, L., Piras, G., Corda, M.G. and Giorgi, O. (2009) The Roman High- and Low-Avoidance Rat Lines Differ in the Acquisition, Maintenance, Extinction, and Reinstatement of Intravenous Cocaine Self-Administration. Neuropsychopharmacology, 34, 1091-1101. http://dx.doi.org/10.1038/npp.2008.43

[41] Driscoll, P., Escorihuela, R.M., Fernández-Teruel, A., Giorgi, O., Schwegler, H., Steimer, TH., Wiersma, A., Corda, M.G., Flint, J., Koolhaas, J.M., Langhans, W., Schulz, P.E., Siegel, J. and Tobeña, A. (1998) Genetic Selection and Differential Stress Responses: The Roman Lines/Strains of Rats. Annals of the New York Academy of Sciences, 851, 501510. http://dx.doi.org/10.1111/j.1749-6632.1998.tb09029.x

[42] Escorihuela, R.M., Fernández-Teruel, A., Tobena, A., Langhans, W., Bättig, K. and Driscoll, P. (1997) Labyrinth Exploration, Emotional Reactivity, and Conditioned Fear in Young Roman/Verh Inbred Rats. Behavior Genetics, 27, 573578. http://dx.doi.org/10.1023/A:1021413200461

[43] Escorihuela, R.M., Fernández-Teruel, A., Gil, L., Aguilar, R., Tobeña, A. and Driscoll, P. (1999) Inbred Roman Highand Low-Avoidance Rats: Differences in Anxiety, Novelty-Seeking, and Shuttlebox Behaviors. Physiology \& Behavior, 67, 19-26. http://dx.doi.org/10.1016/S0031-9384(99)00064-5

[44] Ibias, J. and Pellón, R. (2011) Schedule-Induced Polydipsia in the Spontaneously Hypertensive Rat and Its Relation to Impulsive Behaviour. Behavioural Brain Research, 223, 58-69. http://dx.doi.org/10.1016/j.bbr.2011.04.017

[45] López-Grancha, M. (2005) Mecanismos Neuroconductuales de las Diferencias Individuales en la Polidipsia Inducida por Programa. Ph.D. Thesis, University of Almería, Almería.

[46] Cardona, D., López-Crespo, G., Sánchez-Amate, M.C., Flores, P. and Sánchez-Santed, F. (2011) Impulsivity as LongTerm Sequelae after Chlorpyrifos Intoxication: Time Course and Individual Differences. Neurotoxicity Research, 19, 128-137. http://dx.doi.org/10.1007/s12640-009-9149-3

[47] Navarro, S.V., Gutiérrez-Ferre, V., Flores, P. and Moreno, M. (2014) Activation of Serotonin 5-HT2 ${ }_{\mathrm{A}}$ Receptors Inhibits High Compulsive Drinking on Schedule-Induced Polydipsia. Psychopharmacology, Manuscript Submitted for Pub- lication.

[48] Fineberg, N.A., Potenza, M.N., Chamberlain, S.R., Berlin, H.A., Menzies, L., Bechara, A., Sahakian, B.J., Robbins, T. W., Bullmore, E.T. and Hollander, E. (2010) Probing Compulsive and Impulsive Behaviors, From Animal Models to Endophenotypes: A Narrative Review. Neuropsychopharmacology, 35, 591-604. http://dx.doi.org/10.1038/npp.2009.185

[49] Fineberg, N.A., Chamberlain, S.R., Hollander, E., Boulougouris, V. and Robbins, T.W. (2011) Translational Approaches to Obsessive-Compulsive Disorder: From Animal Models to Clinical Treatment. British Journal of Pharmacology, 164, 1044-1061. http://dx.doi.org/10.1111/j.1476-5381.2011.01422.x 
Scientific Research Publishing (SCIRP) is one of the largest Open Access journal publishers. It is currently publishing more than 200 open access, online, peer-reviewed journals covering a wide range of academic disciplines. SCIRP serves the worldwide academic communities and contributes to the progress and application of science with its publication.

Other selected journals from SCIRP are listed as below. Submit your manuscript to us via either submit@scirp.org or Online Submission Portal.
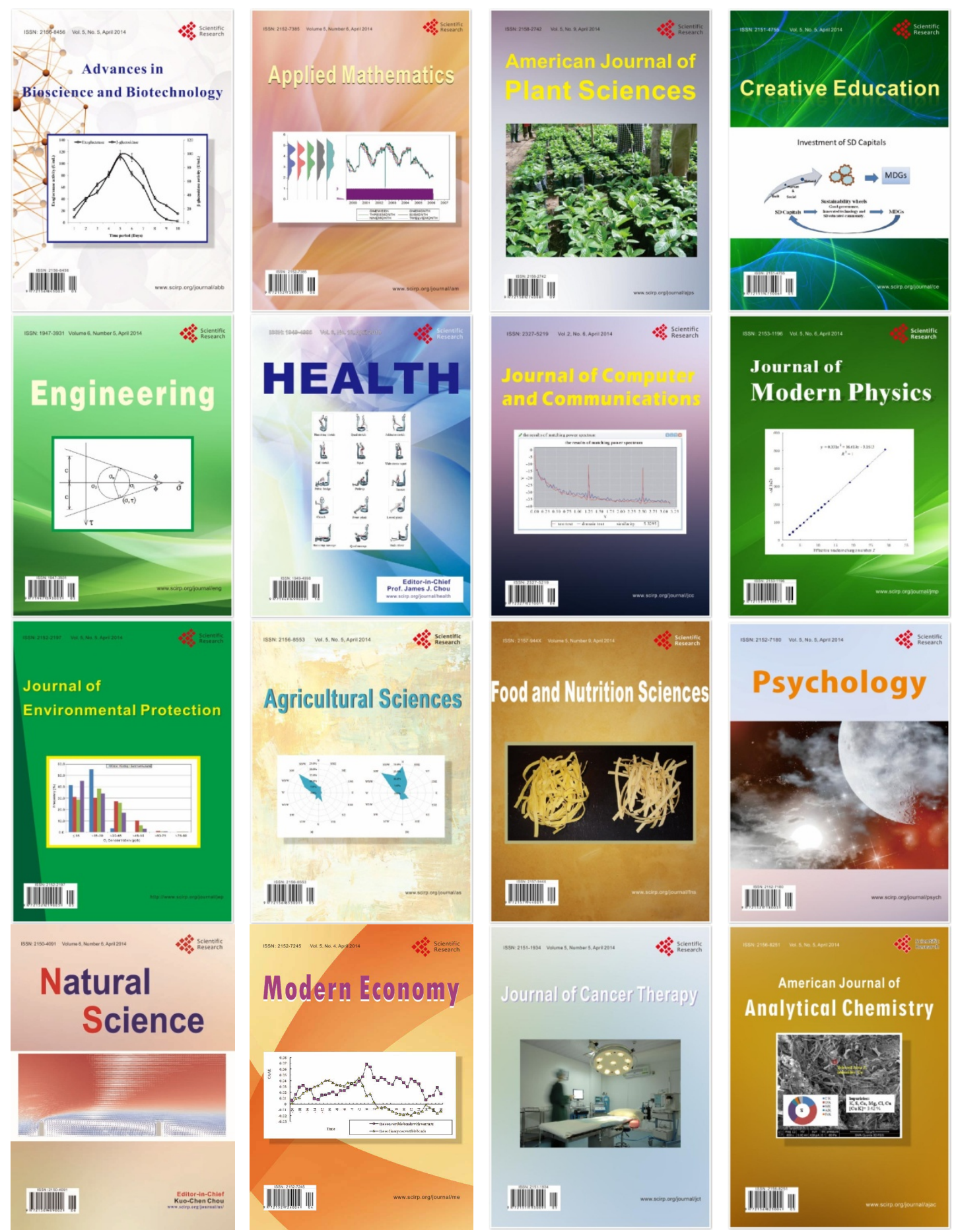